\title{
Review article: Oxidative stress versus antioxidants
}

\author{
Said M. Al-Dalaen ${ }^{1}$, Aiman I. Al-Qtaitat ${ }^{2}$ \\ ${ }^{1}$ Department of Pharmacology, Faculty of Medicine, Mu'tah University, Karak, Jordan \\ ${ }^{2}$ Department of Anatomy \& Histology, Faculty of Medicine, Mu'tah University, Karak, Jordan
}

\section{Email address:}

aldalaensm@yahoo.com (S. M. Al-Dalaen), aimanaq2000@yahoo.com (A. I. Al-Qtaitat)

\section{To cite this article:}

Said M. Al-Dalaen, Aiman I. Al-Qtaitat. Review Article: Oxidative Stress Versus Antioxidants. American Journal of Bioscience and Bioengineering. Vol. 2, No. 5, 2014, pp. 60-71. doi: 10.11648/j.bio.20140205.11

\begin{abstract}
Oxidative stress is a phenomenon that reflects an imbalance between the production of reactive oxygen species and so-called oxidants, and their elimination by protective mechanisms. These are referred to as antioxidative systems which can detoxify the reactive intermediates, or repair the resulting damage causing toxic effects through the production of peroxides and free radicals that damage all cell components. Further, some reactive oxidative species act as cellular messengers in redox signaling that can cause disruptions in normal cellular signaling mechanisms. In humans, oxidative stress is thought to be involved in the development of atherosclerosis, neurodegenerative diseases, such as Alzheimer's and Parkinson's disease, cancer, diabetes mellitus, inflammatory diseases, as well as psychological diseases or aging processes. It is presently accepted that the reactive oxygen species can be beneficial. Depending on the type of oxidants, intensity and time of redox imbalance, as well as on the type of cells, oxidative stress can play a role in the regulation of other important processes. This is achieved through modulation of signal pathways, influencing synthesis of antioxidant enzymes, repair processes, inflammation, or via the immune system, as a way to attack and kill pathogens. This limits the potential for apoptosis and cell proliferation, and thus affects malignant processes. Imprudent administration of antioxidants may therefore have a negative impact on the organism.
\end{abstract}

Keywords: Reactive Oxygen Species, Antioxidants, Oxidative Stress, Redox Stress, Signaling

\section{Summary}

Reactive oxygen species (ROS) are chemically reactive molecules produced by living organisms as a result of normal cellular metabolism. At low to moderate concentrations, they function in physiological cell processes. However, when present in high concentrations, they produce adverse modifications to cell components, such as lipids, proteins, and DNA [1-3]. The shift in the oxidant/antioxidant balance in favor of oxidants is termed "oxidative stress." Oxidative stress contributes to many pathological conditions, including cancer, neurological disorders [4] atherosclerosis, hypertension, ischemia/perfusion [5] diabetes, acute respiratory distress syndrome, idiopathic pulmonary fibrosis, chronic obstructive pulmonary disease [6] and asthma [7-10].

Aerobic organisms have integrated antioxidant systems, which include enzymatic and nonenzymatic antioxidants that are usually effective in blocking harmful effects of ROS. However, in pathological conditions, the antioxidant systems can be overcomed [11].
Table 1. Nomenclature of the various $O_{2}$ forms [12].

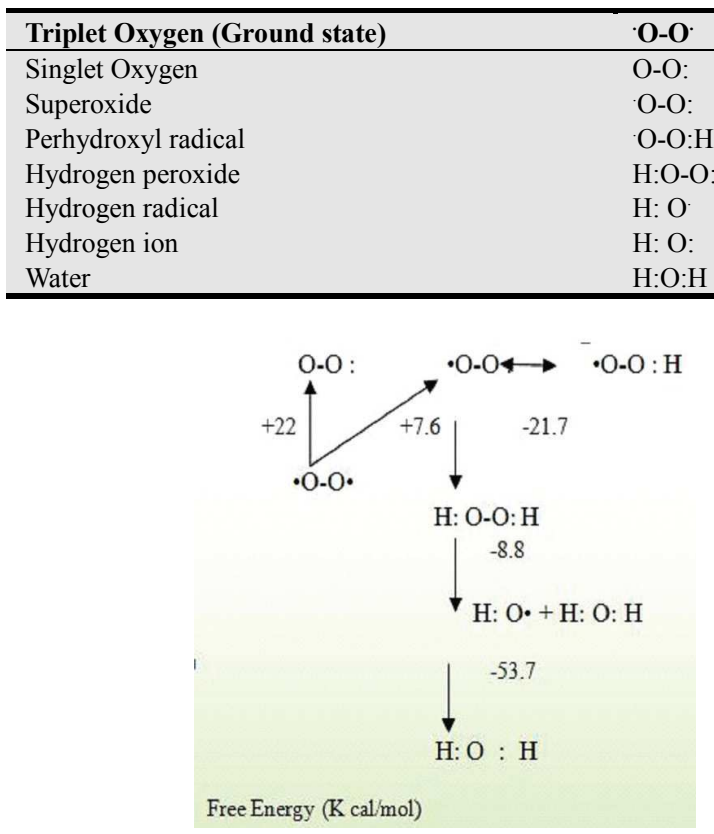

Figure 1. The activation states of oxygen [12]. 


\section{Oxidants}

\subsection{Endogenous Sources of Oxidants}

ROS (shown in Figure 1 and table 1) are produced from the activation of molecular oxygen, intracellularly through multiple mechanisms, as a result of normal cellular metabolism. Their major sources are mitochondria, peroxisomes, endoplasmic reticulum, and the NADPH oxidase (NOX) complex in cell membranes (Figure 2) [13, 14]. ROS can be classified as either free radicals or nonradicals.

Molecules containing one or more unpaired electrons and thus giving reactivity to the molecule are called free radicals. When two free radicals share their unpaired electrons, nonradical forms are created. The three major ROS that are of physiological significance are superoxide anion $\left(\mathrm{O}_{2}^{--}\right)$, hydroxyl radical $(\cdot \mathrm{OH})$, and hydrogen peroxide $\left(\mathrm{H}_{2} \mathrm{O}_{2}\right)[11]$.

Mitochondria convert energy into ATP — a form that can be utilized by the cell. The ATP production process, known as oxidative phosphorylation, involves the transport of protons (hydrogen ions) across the inner mitochondrial membrane by means of the electron transport chain. In the electron transport chain, electrons are passed through a series of proteins via oxidation-reduction reactions, with each acceptor protein along the chain having a greater reduction potential than the previous one. The final destination for an electron along this chain is an oxygen molecule. In normal conditions, oxygen is reduced to produce water. However, in about $1-3 \%$ [11] of electrons passing through the chain, oxygen is prematurely and incompletely reduced, resulting in the superoxide radical $\left(\cdot \mathrm{O}_{2}^{-}\right)$. While superoxide is not particularly reactive, it can inactivate specific enzymes or initiate lipids peroxidation in its protonated form, hydroperoxyl $\mathrm{HO}_{2} \cdot$ [15], $\mathrm{O}_{2}^{-}$itself can also react with $\mathrm{H}_{2} \mathrm{O}_{2}$ and generate $\mathrm{OH}^{-}[16]$. Hydroxyl radical is the most reactive ROS and can damage proteins, lipids, carbohydrates and DNA. It can also initiate lipid peroxidation by taking an electron from polyunsaturated fatty acids. Hydrogen peroxide is also produced by xanthine oxidase, amino acid oxidase, and NADPH oxidase [17] and in peroxisomes by consumption of molecular oxygen in metabolic reactions. In a succession of reactions, called Haber-Weiss and Fenton reactions (Figure 3), $\mathrm{H}_{2} \mathrm{O}_{2}$ can break down to $\mathrm{OH}^{-}$in the presence of transmission metals, such as $\mathrm{Fe}^{+}$or $\mathrm{Cu}^{+}[18]$.

$$
\begin{array}{cc}
\mathrm{Fe}^{+}+\mathrm{O}_{2} \rightarrow \mathrm{Fe}^{2+}+\mathrm{O}_{2} & \text { Haber-Weiss } \\
\mathrm{Fe}^{2+}+\mathrm{H}_{2} \mathrm{O}_{2} \rightarrow \mathrm{Fe}^{+}+\mathrm{OH}^{-}+\mathrm{OH} & \text { Fenton reaction }
\end{array}
$$

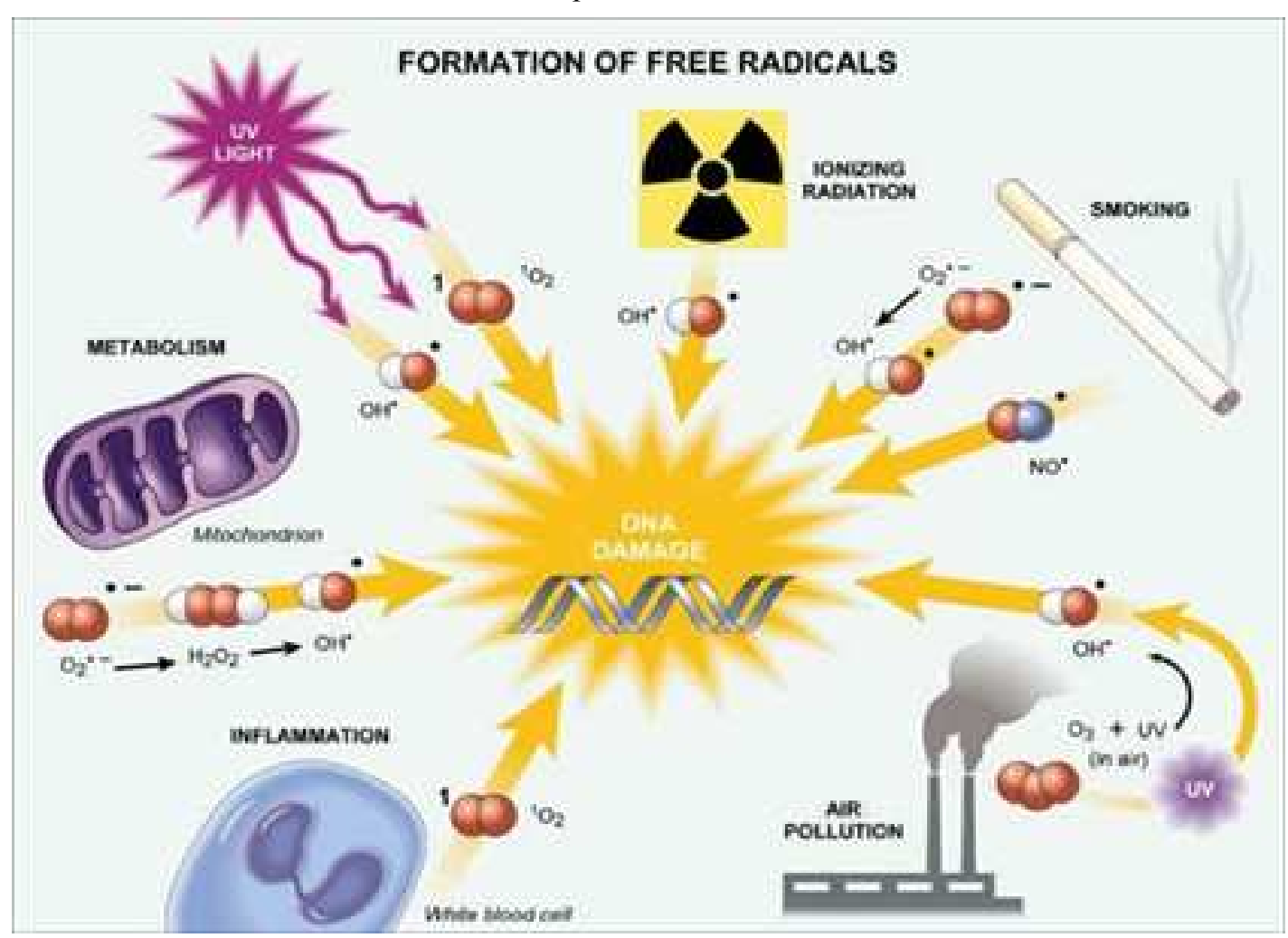

Figure 2. Different ROS sources [13]. 


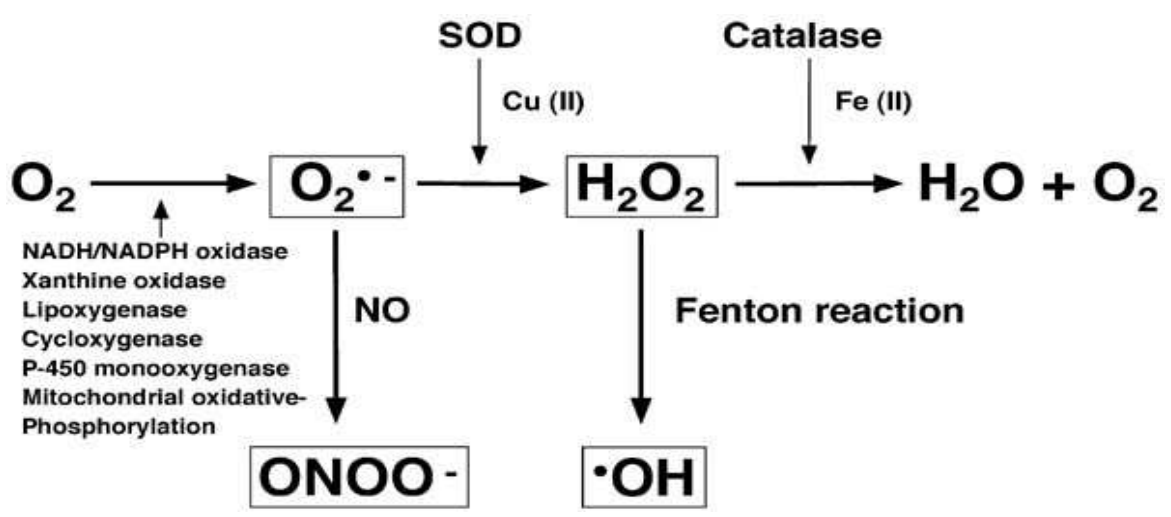

Figure 3. Fenton reaction [18].

Granulocytic enzymes further expand the reactivity of $\mathrm{H}_{2} \mathrm{O}_{2}$ via eosinophil peroxidase and myeloperoxidase (MPO). In activated neutrophils, $\mathrm{H}_{2} \mathrm{O}_{2}$ is consumed by MPO. In the presence of chloride ion, $\mathrm{H}_{2} \mathrm{O}_{2}$ is converted to hypochlorous acid $(\mathrm{HOCl})$, which is highly oxidative and plays an important role in killing of the pathogens in the airways [19]. However, $\mathrm{HOCl}$ can also react with DNA, induce DNAprotein interactions, produce pyrimidine oxidation products and add chloride to DNA bases [20]. Eosinophil peroxidase and MPO also contribute to the oxidative stress through modification of proteins by halogenations, nitration, and protein cross-links via tyrosyl radicals [21].

The peroxyl radicals (ROO.) are another type of oxygenderived free radicals, the simplest of which is hydroperoxyl radical (ROO.) that plays a role in fatty acid peroxidation. Free radicals can trigger lipid peroxidation chain reactions by abstracting a hydrogen atom from a side chain methylene carbon. The lipid radical then reacts with oxygen to produce peroxyl radical. Peroxyl radical initiates a chain reaction and transforms polyunsaturated fatty acids into lipid hydroperoxides, which are very unstable and easily decompose to secondary products, such as aldehydes and malondialdehydes. Isoprostanes are another group of lipid peroxidation products that are generated via the peroxidation of arachidonic acid and have also been found to be elevated in plasma and breath condensates of asthmatics [22].

\subsection{Exogenous Sources of Oxidants}

Exogenous ROS can be produced as a result of smoking [23] as well as exposure to pollutants, ozone [24], hyperoxia [25], heavy metals [26] or radiation [27]. Cigarette smoke contains many oxidants, free radicals and organic compounds, such as superoxide and nitric oxide [24]. Ozone exposure can cause lipid peroxidation and induce influx of neutrophils into the airway epithelium.

Short-term exposure to ozone also causes the release of inflammatory mediators, such as MPO, eosinophil cationic proteins, lactate dehydrogenase and albumin [28].

Hyperoxia refers to conditions characterized by oxygen levels that are higher than normal partial pressure of oxygen in the lungs or other body tissues. This leads to greater production of reactive oxygen and nitrogen species [29].

Heavy metal ions - such as iron, copper, cadmium, mercury, nickel, lead, and arsenic - can induce generation of reactive radicals. This can cause cellular damage via depletion of enzyme activities through lipid peroxidation and reaction with nuclear proteins and DNA, where ROS generated by metal-catalyzed reactions can modify DNA bases. Three base substitutions, $\mathrm{G} \rightarrow \mathrm{C}, \mathrm{G} \rightarrow \mathrm{T}$, and $\mathrm{C} \rightarrow \mathrm{T}$, can occur as a result of oxidative damage by metal ions, such as $\mathrm{Fe}^{2+}, \mathrm{Cu}^{2+}$, and $\mathrm{Ni}^{2+}$. Previous studies have shown that $\mathrm{G}$ $\rightarrow \mathrm{C}$ can be predominantly produced by $\mathrm{Fe}^{2+}$, while $\mathrm{C} \rightarrow \mathrm{T}$ substitution is typically achieved by $\mathrm{Cu}^{2+}$ and $\mathrm{Ni}^{2+}$ [30].

In the presence of $\mathrm{O}_{2}$, ionizing radiation converts hydroxyl radical, superoxide, and organic radicals to hydrogen peroxide and organic hydroperoxide, which can react with redox active metal ions, such as $\mathrm{Fe}$ and $\mathrm{Cu}$, via Fenton reactions, and thus induce oxidative stress [31]. In addition, it can generate damaging intermediates through interaction with water, a process termed radiolysis. Since water comprises $55-60 \%$ of the human body, the probability of radiolysis is quite high under the presence of ionizing radiation. The outcome is conversion of water into hydroxyl radical (-OH), hydrogen peroxide $\left(\mathrm{H}_{2} \mathrm{O}_{2}\right)$, superoxide radical $\left(\mathrm{O}_{2^{-}}\right)$and ultimately oxygen $\left(\mathrm{O}_{2}\right)$ [32]. Moreover, according to the findings of extant studies, various signal transduction molecules-such as extracellular signal-regulated kinase 1 and 2 (ERK1/2), c-Jun N-terminal kinase (JNK), and p38and transcription factors - such as activator protein-1 (AP-1), nuclear factor- $\mathrm{kB}(\mathrm{NF}-\mathrm{\kappa B})$, and $\mathrm{p} 53$ - are activated under effect of ionizing radiation. This results in the expression of radiation response-related genes $[33,34]$.

\section{Oxidative Stress-Induced Cellular Damage}

The targets of ROS damage include all major biomolecular groups, as discussed below.

\subsection{Proteins}

It is well known that ROS can target almost all cellular compounds. According to the findings of several studies, ROS can react with several amino acid residues in vitro, generating a wide range of products - from modified and less active enzymes to denatured, non-functioning proteins [35]. 
Fragmentation of the peptide chain and aggregation of cross-linked reaction products result in an altered electrical charge and increased susceptibility to proteolysis by degradation by specific proteases. Here, the amino acids in a peptide differ in their susceptibility to attack, while the various forms of activated oxygen differ in their potential reactivity [36].

Cysteine and methionine residues in proteins are particularly susceptible to oxidation [37]. For example, oxidation of sulfhydryl groups or methionine residues of proteins causes conformational changes, protein unfolding, and degradation $[38,39]$. Enzymes that have metals at or close to their active sites are especially more sensitive to metal catalyzed oxidation, which can inhibit their activities [40].

\subsection{Lipids}

Oxidative stress can induce lipid peroxidation, causing different arrangement in the membrane lipid bilayer. This results in inactivation of the membrane-bound receptors and enzymes and causes an increase in tissue permeability [41].

Products of lipid peroxidation, such as malodialdehyde and unsaturated aldehydes, are capable of inactivating many cellular proteins by forming protein cross-linkages [42]. This causes depletion of intracellular GSH, induces peroxide production [43] activates epidermal growth factor receptor [44] and induces fibronectin production [45].

\subsection{DNA}

Most of the long-term effects of oxidative stress are inflicted by modifications of DNA [46] which involves degradation of bases, single- or double-stranded DNA breaks, purine, pyrimidine or sugar-bound modifications, mutations, deletions or translocations, and cross-linking with proteins.

Most of these DNA modifications are highly relevant to carcinogenesis, aging, and neurodegenerative, cardiovascular, and autoimmune diseases. DNA damage similar to that induced by oxidative stress can also be induced by ionizing radiation. Promoter regions of genes contain transcription factor-binding sites that have consensus sequences. These contain GC-rich sequences are susceptible for oxidant attacks, which can change the expression of the related gene [47].

Single-base damage by radiation or oxidation, such as 8oxoguanine and thymine glycol, is well known. However, the research focus has recently shifted to some of the more complex lesions, such as tandem DNA lesions, formed at substantial frequency by ionizing radiation and metalcatalyzed $\mathrm{H}_{2} \mathrm{O}_{2}$ reactions.

Under anoxic conditions, the predominant double-base lesion is a species in which C8 of guanine is linked to the 5methyl group of an adjacent 3'-thymine ( $\mathrm{G}$ [8, 5- Me] T) [48]. Most of these oxygen-derived species are produced at a low level by normal aerobic metabolism. As a result of oxidation, 5-methyl cytosine is converted into 5-hydroxy methyl uracil, due to a deamination/oxidation reaction, affecting DNA organization and repair activity [49]. Normal cellular defense mechanisms destroy most of these and any damage to the cells is constantly repaired. However, under the severe levels of oxidative stress that cause necrosis, the damage causes ATP depletion, preventing the control of cell death by apoptosis and causing cell disintegration [50].

\section{Effects of Oxidative Stress on Signal Transduction}

Oxidative stress can cause disruption of the GSH/GSSG ratio, leading to activation of redox sensitive transcription factors, such as the nuclear factor of activated T cells $(\mathrm{NF}-\kappa \mathrm{B})$ and hypoxia-inducible factor 1 (AP-1). Owing to their involvement in inflammatory responses, these factors can facilitate the transmission of information into the cell. Tyrosine kinase receptors, most of the growth factor receptors - such as epidermal growth factor receptor, vascular endothelial growth factor receptor, and receptor for platelet-derived growth factor-as well as protein tyrosine phosphatases and serine/threonine kinases are targets of ROS [51]. Moreover, oxidants can regulate many of the extracellular signal regulated kinases, such as $\mathrm{p} 38$, which are the members of mitogen-activated protein kinase family. As such, they are involved in several processes in the cell, including proliferation, differentiation, and apoptosis. ROS can activate NF- $\kappa \mathrm{B}$ by phosphorylating I $\mathrm{KBs}$ at serine residues, which frees NF- $\mathrm{BB}$ to enter the nucleus to activate gene transcription [52]. A number of kinases have been reported to phosphorylate I $\mathrm{BBs}$; these kinases are targets for oxidative signals to activate NF- $\mathrm{BB}$ [53]. As a result of NF$\kappa \mathrm{B}$ activation via oxidation, several antioxidant defenserelated genes that can participate in immune response are activated. These include IL-1b, IL-6, tumor necrosis factor- $\alpha$, IL-8, and several adhesion molecules. NF- $\mathrm{BB}$ also regulates angiogenesis, proliferation and cell differentiation [54].

\section{Oxidative Stress and Diseases}

\subsection{Aging}

In an attempt to explain the aging process, many theories have been put forward $[55,56]$. However, only the "free radical theory of aging" [57] has gained universal acceptance, as it is supported by the fact that the production of free radicals and the free radical damage increases with age [58]. This theory postulates that free radicals in the body cause oxidative damage to cellular components - a process that results in altered cellular function, compromised tissue and organ function, ultimately leading to death. The free radial theory is also supported by the "rate of living" hypothesis, which inversely links metabolic rate with the longevity of the organisms [59]. This is supported by empirical evidence proved by indicating that oxidative damage to proteins, DNA and lipids increases with age [58]. As free radical-mediated oxidative stress increases with age, it may overwhelm the natural repair systems in the elderly [60]. Thus, it is a major contributor to diseases associated with aging [61]. 


\subsection{Cardiovascular Disease}

Vascular proliferation and inflammation are closely linked [62] and excessive proliferation of vascular cells plays an important role in the pathology of vascular occlusive disease. Free radicals are considered to play a causal role in this process [63]. ROS lead to the oxidation of low density lipoprotein, which accumulates within plaques. It thus contributes to the inflammatory state of atherosclerosis and plays a key role in its pathogenesis [64]. Oxidized-LDL leads to endothelial dysfunction, and can result in either cell growth or apoptotic cell death, causing vasoconstriction. Free radicals have also been implicated in congestive heart failure [65].

\subsection{Diabetes}

Findings of pertinent studies indicate that free radicalinduced damage also plays a role in the development of insulin resistance, $\beta$-cell dysfunction, impaired glucose tolerance, and type II diabetes mellitus [66]. Hyperglycemia can induce oxidative stress through several mechanisms, including glucose autoxidation, the formation of advanced glycation end-products (AGEs), and activation of the polyol pathway [67]. In diabetics, a significant increase in protein glycation (AGE) has been noted. Moreover, evidence suggests that, owing to their accumulation, prevalence of microvascular lesions increases. These are present in diabetic retinopathy, and are also responsible for cardiovascular complications in diabetic patients $[67,68]$. The damage caused by ROS has also been implicated in primary open angle glaucoma (POGA), which is the leading cause of irreversible blindness [69].

\subsection{Cancer}

ROS can activate the initiation, promotion and progression stages of carcinogenesis [70] due to the interaction between free radicals and DNA components. By damaging its bases and the deoxyribose backbone, it causes mutations in crucial genes, thus leading to cancer [71]. In support of this free radical-mediated damage to DNA, either through arrest or induction of transcription, induction of signal transduction pathways, replication errors, and genomic instability occurs. All these phenomena are associated with carcinogenesis [49] which has been found in various cancer tissues. Moreover, there is a direct link between the size of benign tumors and the amount of DNA oxidized product, 8-hydroxyguanine (8$\mathrm{OH}-\mathrm{G}$ ) adduct formation. Understanding this process may be important in explaining the transformation of benign to malignant tumors [72]. In cancer cells, the high level of oxidative stress can induce apoptosis or even necrosis, while, its low level can stimulate cell division and thus promote tumor growth [73].

\subsection{Neurodegenerative Diseases}

A growing body of evidence indicates that free radicals are involved in the initiation of cellular injury observed in neurodegenerative diseases [74] which are characterized by loss of specific neuronal populations. This is often accompanied by intraneuronal damage, as well as extracellular accumulation of fibrillary materials.

\subsection{Parkinson's Disease}

This progressive neurodegenerative movement disorder is considered the most common form of motor system degeneration, affecting approximately $1 \%$ of the population over the age of 65 [75]. Empirical evidence suggests the involvement of free radicals in the pathogenesis of this disease. It has been observed that that oxidation of dopamine yields potentially toxic semiquinones. Moreover, the accelerated metabolism of dopamine by monoamine-oxidase$\mathrm{B}$ may induce an excessive formation of hydrogen peroxide, superoxide anions, and hydroxyl radicals, which not only maintain the oxidative stress level, but also initiate/propagate apoptosis of the dopaminergic neurons [76]. According to the reports in the pertinent literature, Parkinson's disease is associated with increased oxidative damage to DNA [77], proteins [78] and lipids [79].

\subsection{Huntington's Disease}

This inherited autosomal dominant neurodegenerative disease is characterized by uncontrollable movements, irritability and depression [80]. There is a direct evidence to support the involvement of free radicals in the pathogenesis of Huntington's disease, in that increased levels of $\mathrm{F}_{2}$ isoprostanes have been detected in the cerebrospinal fluid of the patients compared to those measured in the healthy persons [81].

\subsection{Alzheimer's Disease}

This neurodegenerative disorder is characterized by cognitive impairment and a gradual loss of memory, language skills, and dementia. It eventually leads to death due to the loss of neurons and synapses [82]. Oxidative damage may play a role in amyloid deposition in Alzheimer's disease, and oxidizing conditions can cause protein crosslinking and aggregation of $\beta$-amyloid protein, tau and other cytoskeletal proteins [83]. The accumulated $\beta$-amyloid can cause oxidation of the nonsaturated carbohydrate side chains of membrane lipids, which leads to the disintegration of the neural membrane. The outcome of this process is cell lysis due to lipid peroxidation [84] which is associated with DNA damage and oxidative modification of proteins in the frontal cortex of brain affected by Alzheimer's disease [85].

\subsection{Stroke}

In the patients that have suffered stroke, neuronal death is caused by the free radicals arising from various sources, such as xanthine oxidase, cyclooxygenase, inflammatory cells and mitochondria [86]. The mitochondrial electron transport chain is altered during ischemia and reperfusion and is also a likely source of free radicals. This can result in increased formation of superoxide radical anions [87]. 
The accumulation of blood borne inflammatory cells, such as neutrophils and monocytes/macrophages, which can occur during reperfusion, can also promote further oxidative stress. This can cause lipid peroxidation and oxidative damage to DNA in ischemic stroke patients [88]. In addition; increased ROS levels can make the brain more susceptible to oxidative stress due to a variety of reasons. For example, the brain could consume a significant amount of the body's oxygen supply, or have a relatively poor antioxidant defense system. Alternatively, it could be enriched in pro-oxidant molecules or contain high concentration of readily peroxidizable lipids [89].

\section{Antioxidants}

Humans have evolved complex antioxidants strategies against prooxidant conditions. The antioxidant defensive system has many components, and a deficiency of any of these components can cause destruction in the overall antioxidant status of an individual [90]. Antioxidants are the molecules that have the ability to counterbalance the effects of oxidants before these attacks the cells (Figure 4). There are highly complex antioxidant systems (enzymatic and nonenzymatic) in human cells, working in collaboration in other to protect the body against free radical damage.

Antioxidants can be endogenous or obtained exogenously, as a part of a diet or through dietary supplements. They can also be consumed as compounds that do not neutralize free radicals, but rather enhance endogenous activity.

An ideal antioxidant should be readily absorbed, quench free radicals, and chelate redox metals. It should also work in both aqueous and/or membrane domains, positively affecting gene expression.

Endogenous antioxidants play a crucial role in maintaining optimal cellular functions. However, under conditions that promote oxidative stress, endogenous antioxidants may not be sufficient. In such cases, dietary antioxidants should be supplied to maintain optimal cellular functions. Some antioxidants can interact with other antioxidants, regenerating their original properties. This process is referred to as the "antioxidant network." [91].

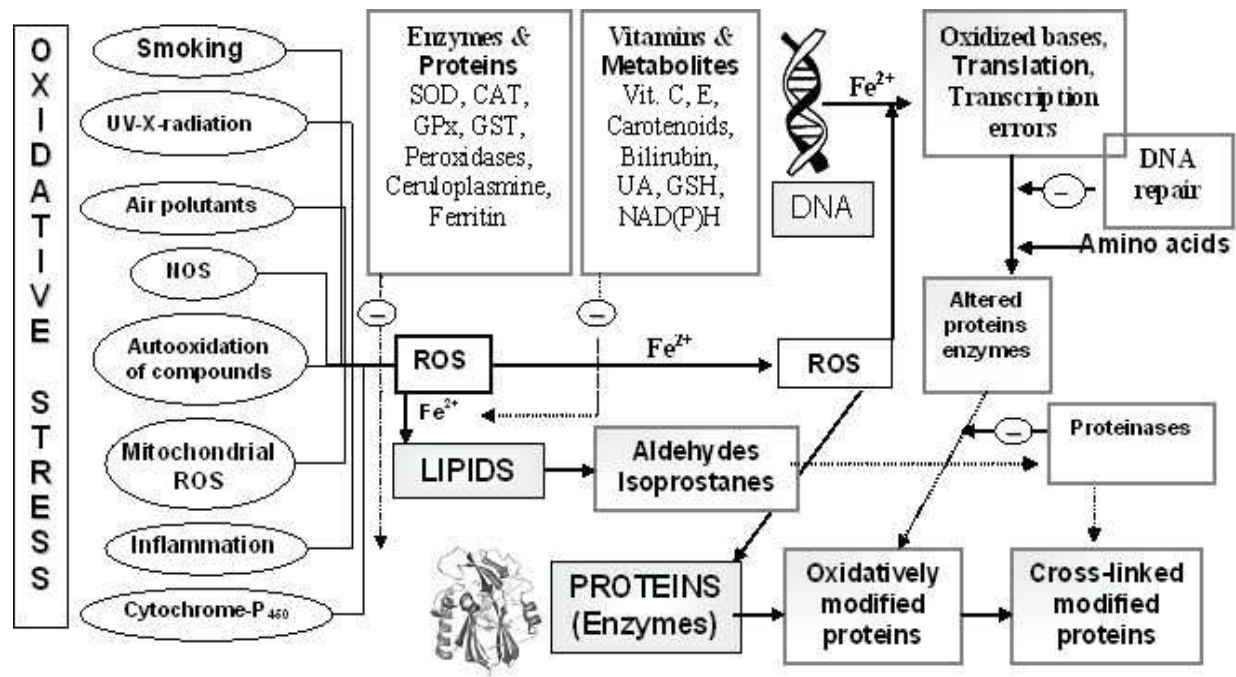

Figure 4. Mutual association between oxidants and antioxidants [92].

\subsection{Enzymatic Antioxidants}

The major enzymatic antioxidants found in the lungs are superoxide dismutases (SODs) (EC 1.15.1.11), catalase (EC 1.11.1.6), glutathione peroxidases (GSH-Pxs) (EC 1.11.1.9) and glutathione-S-transferase (GSTs) (EC 2.5.1.18) [93]. In addition to these major enzymes, other antioxidants, including heme oxygenase-1 (EC 1.14.99.3), and redox proteins, such as thioredoxins (TRXs, EC 1.8.4.10), peroxiredoxins (PRXs, EC 1.11.1.15), and glutaredoxins, have been found to play crucial roles in the pulmonary antioxidant defenses.

Since superoxide is the primary ROS produced in a variety of sources, its dismutation by SOD is of primary importance for each cell. All three forms of SOD - CuZn-SOD, Mn-SOD, and EC-SOD - are widely expressed in human tissues [94]. $\mathrm{Mn}-\mathrm{SOD}$ is localized in the mitochondria matrix. EC-SOD is primarily localized in the extracellular matrix, especially in areas containing high amounts of type I collagen fibers and around pulmonary and systemic vessels. It has also been detected in the bronchial epithelium, alveolar epithelium, and alveolar macrophages [95]. Overall, CuZn-SOD and MnSOD are generally thought to act as bulk scavengers of superoxide radicals. The relatively high EC-SOD level in the lung with its specific binding to the extracellular matrix components may represent a fundamental component of lung matrix protection [96].

$\mathrm{Cu}, \mathrm{Zn}-\mathrm{SOD}$ has two identical subunits, with a molecular weight of $32 \mathrm{kDa}$. Each subunit contains a dinulcear metal cluster, comprising of copper and zinc ions as the active site, and it specifically catalyzes the dismutation of the superoxide anion to oxygen and water [97]. The mitochondrial Mn-SOD is a homotetramer with a molecular weight of $96 \mathrm{kDa}$ and contains one manganese atom per subunit. It vacillates from Mn (III) to Mn (II) and back to Mn (III) during the two-step 
dismutation of superoxide [97]. Extra-cellular superoxide dismutase contains copper and zinc. It is a tetrameric secretary glycoprotein, characterized by a high affinity for certain glycosaminoglycans, such as heparin and heparin sulphate. However, its regulation in mammalian tissues occurs primarily in a manner coordinated by cytokines, rather than as a response to oxidative stress [97].

$\mathrm{H}_{2} \mathrm{O}_{2}$ produced by the action of SODs or oxidases, such as xanthine oxidase, is reduced to water by catalase and the GSH-Px. Catalase exists as a tetramer composed of four identical monomers, each of which contains a heme group at the active site. Degradation of $\mathrm{H}_{2} \mathrm{O}_{2}$ is accomplished via the conversion between two conformations of catalaseferricatalase (iron coordinated to water) and compound I (iron complexed with an oxygen atom). Catalase also binds NADPH as a reducing equivalent to prevent oxidative inactivation of the enzyme (formation of compound II) by $\mathrm{H}_{2} \mathrm{O}_{2}$ as it is reduced to water [98]. Catalase has one of the highest turnover rates of all enzymes; one molecule of catalase can convert approximately 6 million molecules of hydrogen peroxide to water and oxygen each minute [97]. The GSH-Pxs are a family of tetrameric enzymes that contain the unique amino acid selenocysteine within the active sites and use glutathione (GSH) to reduce $\mathrm{H}_{2} \mathrm{O}_{2}$ and lipid peroxides to their corresponding alcohols. While four GSHPxs have been described, encoded by different genes, GSHPx-1 (cellular GSH-Px) is ubiquitous. It reduces $\mathrm{H}_{2} \mathrm{O}_{2}$ and fatty acid peroxides, but not esterified peroxyl lipids [99]. Esterified lipids are reduced by membrane-bound GSH-Px-4 using several different thiols as reducing equivalents. GSHPx-2 (gastrointestinal GSH-Px) is localized in gastrointestinal epithelial cells, where it serves to reduce dietary peroxide levels [100]. GSH-Px-3 (extracellular GSH-Px) is the only member of the GSH-Px family that resides in the extracellular compartment and is believed to be one of the most important extracellular antioxidant enzymes in mammals [101].

GSTs can inactivate secondary metabolites, such as unsaturated aldehydes and hydroperoxides. Presently, three major families of GSTs are recognized-cytosolic GST, mitochondrial GST [102, 103] and membrane-associated microsomal GST that plays a role in eicosanoid and GSH metabolism [104]. During non-stressed conditions, $\mathrm{Mu}$ and Pi classes of cytosolic GSTs can interact with kinases Ask1 and JNK, respectively, resulting in their inhibition [105]. The dissociation of GSTP1 from JNK in response to oxidative stress [106] results in the recovery of peroxiredoxin VI (PRX VI) enzyme activity through glutathionylation of the oxidized protein [107].

The enzymatic antioxidants also include six different types of PRXs, each playing a major role in the protection of alveolar epithelium, PRX VI in particular [108]. PRX V has been found to function as a peroxynitrite reductase [109]; according to some authors, it may also function as a potential protective compound in the development of ROS-mediated lung injury [110].

\subsection{Nonenzymatic Antioxidants}

\subsubsection{Vitamin E ( $\alpha$-Tocopherol)}

This fat-soluble vitamin is considered a major powerful membrane-bound antioxidant, employed by the cell [111] as a protection against lipid peroxidation [112]. During the antioxidant reaction, $\alpha$-tocopherol is converted into $\alpha$ tocopherol radical by the donation of labile hydrogen to a lipid or lipid peroxyl radical. Thus, the $\alpha$-tocopherol radical can be reduced to the original $\alpha$-tocopherol form by ascorbic acid [113].

\subsubsection{Vitamin C (Ascorbic Acid)}

As it is water-soluble, Vitamin $\mathrm{C}$ acts in the aqueous environments of the body, along with the antioxidant enzymes. Vitamin $\mathrm{C}$ cooperates with Vitamin $\mathrm{E}$ to regenerate $\alpha$-tocopherol from $\alpha$-tocopherol radicals in membranes and lipoproteins [112] (Figure 5). By raising intracellular glutathione levels, it also plays an important role in protein thiol group protection against oxidation [114]. Yuanyuan et al. (2014) [115] reported that vitamin C decreased ROS and DNA damage of severe CAP PBMC in vitro, and vitamin $\mathrm{C}$ decreased TNF- $\alpha$ and IL- 6 in whole blood cells from severe CAP.

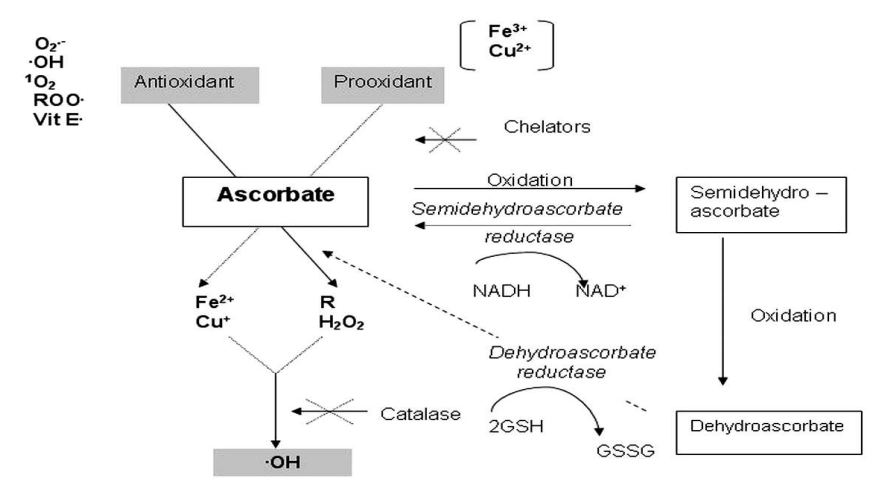

Figure 5. Ascorbic acid - antioxidant and potential prooxidant properties [92].

\subsubsection{Carotenoids ( $\beta$-Carotene)}

These are mainly colored pigments present in plants and microorganisms. Epidemiological studies have revealed that a diet rich in carotenoids is correlated with a lower risk of age-related diseases [116]. Primarily, $\beta$-carotene has been found to react with peroxyl (ROO.) to prevent damage in lipophilic compartments [117] hydroxyl (.OH), and superoxide $\left(\mathrm{O}_{2}^{-}\right.$.) radicals [118]. The antioxidant activity of carotenoids arises due to their ability to delocalize unpaired electrons, and thus quench singlet oxygen without degradation [119]. The efficacy of carotenoids with respect to physical quenching is related to the number of conjugated double bonds present in the molecule. Both $\beta$-Carotene and retinoic acid are capable of regulating different transcription factors [120], $\beta$-Carotene inhibits the oxidant-induced NF- $\kappa B$ activation and interleukin (IL)- 6 and tumor necrosis factor- $\alpha$ production. On the other hand, retinoic acid can affect cell apoptosis, arrest cell cycle, or both [121, 122]. 


\subsubsection{Thiol Antioxidants}

Glutathione (GSH) is the major thiol-disulphide redox intracellular multifunctional soluble antioxidant of the cell. It can be found abundant in cytosol, nuclei, and mitochondria [123]. It can be found in the reduced form, i.e., as GSH, or in the oxidized form, known as GSSG (glutathione disulphide). The antioxidant capacity of thiol compounds is attributed to the presence of sulfur atom, which can easily accommodate the loss of a single electron [124]. As oxidized glutathione (GSSG) is accumulated inside the cells, the GSH/GSSG ratio is a reliable indicator of oxidative stress of an organism [125]. It can act as a co-factor for several detoxifying enzymes, participate in amino acid transport across plasma membrane, scavenge hydroxyl radical and singlet oxygen directly, and regenerate Vitamin $\mathrm{C}$ and $\mathrm{E}$ back to their active forms [123]. In addition, evidence suggests that GSH protects cells against apoptosis by interacting with proapoptotic and antiapoptotic signaling pathways. It also regulates and activates several transcription factors, such as AP-1, NF- $\mathrm{BB}$, and Sp-1 [123]. Thioredoxin (TRX) is another thiol antioxidant with oxidoreductase and ubiquitous activity in both mammalian and prokaryotic cells. In its reduced form, it contains two adjacent - $\mathrm{SH}$ groups that are converted to a disulphide unit in oxidized TRX when it undergoes redox reactions with multiple proteins. TRX and GSH may have overlapping as well as compartmentalized functions in the activation and regulation of transcription factors [1]. $\alpha$-Lipoic is another thiol disulphide derivative of octanoic acid antioxidant. It is both water- and fat-soluble and is widely distributed in both cellular membranes and the cytosol of eukaryotic and prokaryotic cells [126]. Thus, it is readily absorbed from the diet and is converted rapidly to its reduced form, dihydrolipoic acid, which is a stronger antioxidant than lipoic acid. Both $\alpha$-Lipoic and dihydrolipoic acids are powerful antioxidants. They can scavenge free radicals, chelate metal ion, act in recycling antioxidants and repair protein damage due to oxidative stress either in the cytosol or hydrophobic domains [127].

\subsubsection{Melatonin}

This is a neurohormone that is derived from tryptophan mainly in the pineal gland. One of the major functions of melatonin is scavenging free radicals in oxygen metabolism, thereby potentially protecting against free radical-induced damage to DNA, proteins and membranes. Owing to these properties, it has the potential to play an important role in the reduction of free radical-mediated diseases [128].

\section{Conclusion}

Extant research has led to a universal agreement that oxidative damage to proteins, lipids, and DNA occurs as a result of ROS overproduction. These are highly reactive due to the unpaired electrons in their structure that allow them to react with several biological macromolecules in cell, thus altering their functions. ROS are produced by cellular metabolic reactions that use oxygen and shift the balance in oxidant/antioxidant status in favor of the oxidants. In addition, a variety of environmental factors, such as air pollutants or cigarette smoke, can result in the production of ROS, which can also affect the expression of several genes by upregulation of redox-sensitive transcription factors and chromatin remodeling through alteration in histone acetylation/deacetylation. The human body deals with the pathological effects of ROS by utilizing the endogenous antioxidant enzymatic system and by the ingestion of exogenous antioxidants in the diet. If the oxidative stress exceeds the protection afforded by antioxidants, the aging process and some of the diseases associated with it—such as cardiovascular diseases, neurodegenerative diseases, diabetes and cancer - can accelerate. Regulation of redox state is critical for cell viability, activation, and proliferation, as well as organ function.

\section{References}

[1] Valko M, Rhodes CJ, Moncol J, Izakovic M, Mazur M. Free radicals, metals and antioxidants in oxidative stress-induced cancer. Chem. Biol. Interact., 2006; 160:1-40.

[2] Marnett LJ. Lipid peroxidation dDNA damage by malondialdehyde. Mutat. Res., 1999; 424:83-95.

[3] Stadtman ER. Role of oxidant species in aging. Curr. Med. Chem., 2004; 11:1105-1112

[4] Jenner P. Oxidative stress in Parkinson's disease. Ann Neurol., 2003; 53: S26-S36.

[5] Kasparova S, Brezova V, Valko M, Horecky J, Mlynarik V, et al. Study of the oxidative stress in a rat model of chronic brain hypoperfusion. Neurochem. Int., 2005; 46:601-611.

[6] Asami S, Manabe H, Miyake J, Tsurudome Y, Hirano T, et al. Cigarette smoking induces an increase in oxidative DNA damage, 8-hydroxydeoxyguanosine, in a central site of the human lung. Carcinogenesis. 1997; 18:1763-1766.

[7] Comhair SA, Ricci KS, Arroliga M, Lara AR, Dweik RA, et al Correlation of systemic superoxide dismutase deficiency to airflow obstruction in asthma. Am. J. Respir. Crit. Care Med., 2005; 172:306-313.

[8] Dut R, Dizdar EA, Birben E, Sackesen C, Soyer OU, Besler T, Kalayci O. Oxidative stress and its determinants in the airways of children with asthma. Allergy. 2008; 63:1605-1609.

[9] Ercan H, Birben E, Dizdar EA, Keskin O, Karaaslan C, et al. Oxidative stress and genetic and epidemiologic determinants of oxidant injury in childhood asthma. J. Allergy Clin. Immunol., 2006; 118:1097-1104.

[10] Fitzpatrick AM, Teague WG, Holguin F, Yeh M, Brown LA. Severe Asthma Research Program. Airway glutathione homeostasis is altered in children with severe asthma: evidence for oxidant stress. J Allergy Clin Immunol. 2009; 123:146-152.

[11] Esra B, Umit S, Cansin S, Serpil E and Omer K. Oxidative Stress and Antioxidant Defense. WAO Journal 2012; 5:9-19

[12] Fatmah AM, Siti BB, Zariyantey AH, Nasar A and Jamaludin $M$. The Role of Oxidative Stress and Antioxidants in Diabetic Complications. SQU Med J, 2012; 12: 5-18. 
[13] Han D, Williams E, Cadenas E. "Mitochondrial respiratory chain-dependent generation of superoxide anion and its release into the intermembrane space". Biochem., J. 2001; 353 (Pt 2): 411-6.

[14] Li X, Fang P, Mai J, "et al. "Targeting mitochondrial reactive oxygen species as novel therapy for inflammatory diseases and cancers". J. Hematol. Oncol., 2013; 6 (19).

[15] Van Raamsdonk JM, Hekimi S. "Deletion of the mitochondrial superoxide dismutase sod-2 extends lifespan in Caenorhabditis elegans". PLoS Genet., 2009; 5 (2): e1000361.

[16] Liochev SI, Fridovich I. The Haber-Weiss cycled70 years later: an alternative view. Redox Rep., 2002; 7:55-57.

[17] Granger DN. Role of xanthine oxidase and granulocytes in ischemia reperfusion injury. Am. J. Physiol., 1988; 255:H1269-H1275.

[18] Fenton HJH. Oxidation of tartaric acid in the presence of iron. J. Chem. Soc., 1984; 65:899-910.

[19] Klebanoff SJ. Myeloperoxidase: friend and foe. J. Leukoc. Biol., 2005; 77:598-625.

[20] Kulcharyk PA, Heinecke JW. Hypochlorous acid produced by the myeloperoxidase system of human phagocytes induces covalent cross-links between DNA and protein. Biochemistry $2001 ; 40: 3648-3656$.

[21] Brennan ML, Wu W, Fu X, Shen Z, Song W, et al. A tale of two controversies: defining both the role of peroxidases in nitrotyrosine formation in vivo using eosinophil peroxidase and myeloperoxidase deficient mice, and the nature of peroxidase-generated reactive nitrogen species. J. Biol. Chem., $2002 ; 277: 17415-17427$.

[22] Wood LG, Fitzgerald DA, Gibson PG, Cooper DM, Garg ML. Lipid peroxidation as determined by plasma isoprostanes is related to disease severity in mild asthma. Lipids 2000; 35:967-974.

[23] Cho AK, Sioutas C, Miguel AH, Kumagai Y, Schmitz DA, et al. Redox activity of airborne particulate matter at different sites in the Los Angeles Basin. Environ. Res., 2005 ; 99:40-47.

[24] Church DF, Pryor WA. Free-radical chemistry of cigarette smoke and its toxicological implications. Environ Health Perspect., 1985' 64:111-126.

[25] Comhair SA, Thomassen MJ, Erzurum SC. Differential induction of extracellular glutathione peroxidase and nitric oxide synthase 2 in airways of healthy individuals exposed to $100 \%$ O2 or cigarette smoke. Am J Respir Cell Mol Biol. $2000 ; 23: 350-354$.

[26] Stohs SJ, Bagchi D. Oxidative mechanisms in the toxicity of metal ions. Free Radic. Biol. Med., 1995; 18:321-336.

[27] Chiu SM, Xue LY, Friedman LR, Oleinick NL. Copper ionmediated sensitization of nuclear matrix attachment sites to ionizing radiation. Biochemistry. 1993; 32:6214-6219

[28] Hiltermann JT, Lapperre TS, van Bree L, Steerenberg PA, Brahim JJ, et al. Ozone-induced inflammation assessed in sputum and bronchial lavage fluid from asthmatics: a new noninvasive tool in epidemiologic studies on air pollution and asthma. Free Radic. Biol. Med., 1999; 27:1448-1454.

[29] Matthay MA, Geiser T, Matalon S, Ischiropoulos H. Oxidantmediated lung injury in the acute respiratory distress syndrome. Crit Care Med. 1999; 27:2028-2030.

[30] Reid TM, Feig DI, Loeb LA. Mutagenesis by metal-induced oxygen radicals. Environ. Health Perspect., 1994; 102 (suppl 3):57-61.

[31] Biaglow JE, Mitchell JB, Held K. The importance of peroxide and superoxide in the X-ray response. Int. J. Radiat. Oncol. Biol. Phys., 1992; 22:665-669.

[32] Guo G, Yan-Sanders Y, Lyn-Cook BD, Wang T, Tamae D, et al. Manganese superoxide dismutase-mediated gene expression in radiation induced adaptive responses. Mol. Cell Biol., 2003; 23:2362-2378.

[33] Azzam EI, de Toledo SM, Spitz DR, Little JB. Oxidative metabolism modulates signal transduction and micronucleus formation in bystander cells from a-particle irradiated normal human fibroblasts. Cancer Res., 2002; 62:5436-5442.

[34] Dent P, Yacoub A, Fisher PB, Hagan MP, Grant S. MAPK pathways in radiation responses. Oncogene. 2003; 22:58855896

[35] Butterfield DA, Howard B, Subramaniam R, Hall N, Hensley $\mathrm{K}$, Yatin S, et al. Structural and functional changes in proteins induced by free radicalmediated oxidative stress and protective action of the antioxidants N-tert-butyl-alphaphenylnitrone and vitamin E. Ann. N. Y. Acad. Sci., 1998; 854:448-62.

[36] Oxidative stress. From: http://www.plantstress.com/ Articles. 1996; Accessed

[37] Dean RT, Roberts CR, Jessup W. Fragmentation of extracellular and intracellular polypeptides by free radicals. Prog. Clin. Biol. Res., 1985; 180:341-350

[38] Keck RG. The use of t-butyl hydroperoxide as a probe for methionine oxidation in proteins. Anal. Biochem., 1996; 236:56-62.

[39] Lyras L, Cairns NJ, Jenner A, Jenner P, Halliwell B. An assessment of oxidative damage to proteins, lipids, and DNA in brain from patients with Alzheimer's disease. J. Neurochem., 1997; 68:2061-2069.

[40] Stadtman ER. Metal ion-catalyzed oxidation of proteins: biochemical mechanism and biological consequences. Free Radic. Biol. Med., 1990; 9:315-325.

[41] Giugliano D, Ceriollo A, Paolisso G. Oxidative stress and diabetic vascular complications. Diabetes Care 1996; 19:25767.

[42] Esterbauer H, Koller E, Slee RG, Koster JF. Possible involvement of the lipid-peroxidation product 4hydroxynonenal in the formation of fluorescent chromolipids. Biochem. J. 1984; 239:405-409

[43] Uchida K, Shiraishi M, Naito Y, Torii Y, Nakamura Y, Osawa T. Activation of stress signaling pathways by the end product of lipid peroxidation. 4-hydroxy-2-nonenal is a potential inducer of intracellular peroxide production. J. Biol. Chem., 1999; 274:2234-2242

[44] Suc I, Meilhac O, Lajoie-Mazenc I, Vandaele J, Jurgens G, Salvayre R, Negre-Salvayre A. Activation of EGF receptor by oxidized LDL. FASEB J. 1998; 12:665-671.

[45] Tsukagoshi H, Kawata T, Shimizu Y, Ishizuka T, Dobashi K, Mori M. 4-Hydroxy-2-nonenal enhances fibronectin 
production by IMR-90 human lung fibroblasts partly via activation of epidermal growth factor receptor-linked extracellular signal-regulated kinase p44/42 pathway. Toxicol .Appl. Pharmacol., 2002; 184:127-135.

[46] Sies, H. "Oxidative stress: introductory remarks". In H. Sies, (Ed.). Oxidative Stress. London: Academic Press. 1985; pp. 17.

[47] Ghosh R, Mitchell DL. Effect of oxidative DNA damage in promoter elements on transcription factor binding. Nucleic Acids Res., 1999; 27:3213-3218.

[48] Docampo, R. "Antioxidant mechanisms". In J. Marr and M. Müller, (Eds.). Biochemistry and Molecular Biology of Parasites. London: Academic Press. 1995; pp. 147-160.

[49] Cooke MS, Evans MD, Dizdaroglu M, Lunec J. 2003. Oxidative DNA damage: mechanisms, mutation, and disease. FASEB J. 17:1195-1214.

[50] Seaver LC, Imlay JA. "Are respiratory enzymes the primary sources of intracellular hydrogen peroxide?". J. Biol. Chem., 2004; 279 (47): 48742-50.

[51] Sun T, Oberley LW. Redox regulation of transcriptional activators. Free Radic. Biol. Med., 1996; 21:335-348.

[52] Perkins ND. Integrating cell-signalling pathways with NFkappaB and IKK function. Nat. Rev. Mol. Cell Biol., 2007; 8:49-62.

[53] Gilmore TD. Introduction to NF-kappaB: players, pathways, perspectives. Oncogene. 2006; 25:6680-6684.

[54] Akira S, Kishimoto A. NF-IL6 and NF-kB in cytokine gene regulation. Adv. Immunol., 1997; 65:1-46.

[55] Balaban RS, Nemoto S, Finkel T. Mitochondria, Oxidants, and Aging. Cell Vol, 2005; 120:483-95.

[56] Sohal RS, Mockett RJ, Orr WC. Mechanisms of Aging: An appraisal of the oxidative stress hypothesis. Free Rad. Biol. Med., 2002; 33:575-86

[57] Harman D. Ageing: a theory based on free radical and radiation chemistry. J. Gerontol., 1956; 2:298-300.

[58] Sohal RS, Weindruch R. Oxidative stress, caloric restriction, and ageing. Science, 1996; 273:59-63.

[59] Ku HH, Brunk UT, Sohal RS. Relationship between mitochondrial superoxide and hydrogen peroxide production and longevity of mammalian species. Free Rad. Biol. Med., $1993 ; 15: 621-7$.

[60] Kowald A, Kirkwood TB. Accumulation of defective mitochondria through delayed degradation of damaged organelles and its possible role in ageing of post-mitotic and dividing cells. J. Theor. Biol., 2000; 202:145-60.

[61] Ames BN, Shigenaga MK, Hagen TM. Oxidants, antioxidants and degenerative diseases of aging. Proc. Natl. Acad. Sci., 1993; 90:7915-22.

[62] Dzau VJ, Braun-Dullaeus RC, Sedding DG. Vascular proliferation and atherosclerosis: new perspectives and therapeutic strategies. Nat. Ned., 2002; 8:1249-56.

[63] Schachinger V, Zeiher AM. Atherogenesis-recent insights into basic mechanisms and their clinical impact. Nephrol. Dial. Transplant., 2002; 17:2055-64
[64] Galle J, Hansen-Hagge T, Wanner C, Seibold S. Impact of oxidized low density lipoprotein on vascular cells. Atherosclerosis, 2006; 185:219-26.

[65] Elahi MM, Matata BM. Free radicals in blood: Evolving concepts in the mechanism of ischemic heart disease. Arch. Biochem. Biophys., 2006; 450:78-88.

[66] Wright Ejr, Scism-Bacon JL, Glass LC. Oxidative stress in type 2 diabetes: the role of fasting and postprandial glycemia. Int. J. Clin. Prac., 206; 60:308-14.

[67] Jay D, Hitomi H, Griendling KK. Oxidative stress and diabetic cardiovascular complications. Free Rad. Biol. Med., 2006; 40:183-92.

[68] Wautier JL, Schmidt AM. Protein glycation. Circulation Res, 2004; 95:233-8.

[69] Izzotti A, Bagnis A, Saccà SC. The role of oxidative stress in glaucoma. Mutation Res., 2006; 612:105-14.

[70] Klaunig JE, Kamendulis LM. The role of oxidative stress in carcinogenesis. Ann. Rev. Pharmacol. Toxicol., 2004; 44:23967.

[71] Dizdaroglu M, Jaruga P, Birincioglu M, et al. Free-radicalinduced damage to DNA: mechanisms and measurement. Free Rad. Bio. Med., 202; 32:1102-15.

[72] Loft S, Poulsen HE. Cancer risk and oxidative DNA damage in man. J. Mol. Med., 1996; 74:297-312.

[73] Dreher D, Junod AF. Role of oxygen free radicals in cancer development. Eur. J. Cancer, 1996; 32A:30-8.

[74] Emerit J, Edeas M, Bricaire F. Neurodegenerative diseases and oxidative stress. Biomed. Pharmacother., 2004; 58:39-46.

[75] Moore DJ, West AB, Dawson VL, et al. Molecular pathology of Parkinson's disease. Annu. Rev. Neurosci., 2005; 28:57-87.

[76] Hald A, Lotharius J. Oxidative stress and inflammation in Parkinson's disease: is there a causal link? Exp. Neurol., 2005; 193:279-90.

[77] Migliore L, Petrozzi L, Lucetti C, et al. Oxidative damage and cytogenetic analysis in leukocytes of Parkinson's disease patients. Neurology, 2002; 58:1809-15.

[78] Choi J, Sullards MC, Olzmann JA, et al. Oxidative damage of DJ-1 is linked to sporadic Parkinson and Alzheimer diseases. J. Biol. Chem., 2006; 281:10816-24.

[79] Agil A, Durản R, Barrero F, et al. Plasma lipid peroxidation in sporadic Parkinson's: Role of the L-dopa. J. Neuro. Scien., 2006; 240:31-6.

[80] Margolis RL, Ross CA. Diagnosis of Huntington's disease. Clin. Chem., 2003 ; 49:1726-32.

[81] Montine TJ, Beal MF, Robertson D, et al. Cerebrospinal fluid $\mathrm{F}_{2}$-isoprostanes are elevated in Huntington's disease. Neurology, 1999; 52:1104-5.

[82] Selkoe DJ. Alzheimer disease: mechanistic understanding predicts novel therapies. Ann. Intern. Med., 2004; 140:627-38.

[83] Troncoso JC, Costello A, Watson AL et al. In vitro polymerization of oxidized tau into filaments. Brain Res., 1993; 613:313-6. 
[84] Völkel W, Sicilia T, Pähler A, et al. Increased brain levels of 4-hydroxy-2-nonenal glutathione conjugates in severe Alzheimer's disease. Neurochem. Intern., 2006; 48:679-686.

[85] Korolainen MA, Goldsteins G, Tuula A, et al. Oxidative modification of proteins in the frontal cortex of Alzheimer's disease brain. Neuro. Biol. Aging, 2006; 27:42-53.

[86] Alexandrova M, Bochev P, Markova V, et al. Dynamics of free radical processes in acute ischemic stroke: influence on neurological status and outcome. J. Clin. Neurosci., 2004; 11:501-6.

[87] Simms NR, Anderson MF. Mitochondrial contributions to tissue damage in stroke. Neurochem. Int., 2002; 40:511-26.

[88] Mariani E, Polidori MC, Cherubini A, et al. Oxidative stress in brain aging, neurodegenerative and vascular diseases: An overview. J. Chromat. B, 2005; 827:65-75

[89] Cherubini A, Ruggiero C, Cristina M, et al. Potential markers of oxidative stress in stroke. Free Rad. Biol. Med., 2005; 39:841-52.

[90] Yanli L., Richard W. B., Matthew R. B., Furong D., Lili T. and Lina M. Positive Relationship between Total Antioxidant Status and Chemokines Observed in Adults. Oxidative Medicine and Cellular Longevity Article ID 693680, 2014; 6 pages

[91] Sies H, Stahl W, Sevanian A. Nutritional, dietary and postprandial oxidative stress. J. Nutr., 2005; 135:969-72.

[92] Ďuračková Z. Some current insights into oxidative Stress (Review). Physiol. Res., 2010 ; 59: 459-469

[93] Halliwell, B.; Gutteridge, J.M.C. Free Radicals in Biology and Medicine; 2007; Clarendon Press: Oxford, UK.

[94] Landis GN, Tower J. Superoxide dismutase evolution and life span regulation. Mech. Ageing Dev., 2005; 126:365-79.

[95] Kinnula VL. Production and degradation of oxygen metabolites during inflammatory states in the human lung. Curr. Drug Targets Inflamm. Allergy. 2005; 4:465-470

[96] Zelko IN, Mariani TJ, Folz RJ. Superoxide dismutase multigene family: a comparison of the CuZn-SOD (SOD1), Mn-SOD (SOD2), and EC-SOD (SOD3) gene structures, evolution, and expression. Free Radic. Biol. Med., 2002; 33:337-349.

[97] Mates JM, Perez-Gomez C and De Castro IN. Antioxidant enzymes and human diseases. Clin. Biochem., 999 ; 132:595603 .

[98] Kirkman HN, Rolfo M, Ferraris AM, Gaetani GF. Mechanisms of protection of catalase by NADPH. Kinetics and stoichiometry. J. Biol. Chem., 1999; 274:13908-13914

[99] Arthur JR. The glutathione peroxidases. Cell Mol Life Sci. $2000 ; 57: 1825-1835$

[100] Chu FF, Doroshow JH, Esworthy RS. Expression, characterization, and tissue distribution of a new cellular selenium-dependent glutathione peroxidase, GSHPx-GI. J. Biol. Chem., 1993; 268:2571-2576

[101] Comhair SA, Bhathena PR, Farver C, Thunnissen FB, Erzurum SC. Extracellular glutathione peroxidase induction in asthmatic lungs: evidence for redox regulation of expression in human airway epithelial cells. FASEB J. 2001;
$15: 70-78$

[102] Ladner JE, Parsons JF, Rife CL, Gilliland GL, Armstrong RN. Parallel evolutionary pathways for glutathione transferases: structure and mechanism of the mitochondrial class kappa enzyme rGSTK1-1. Biochemistry. 2004; 43:52-61

[103] Robinson A, Huttley GA, Booth HS, Board PG. Modelling and bioinformatics studies of the human kappa class glutathione transferase predict a novel third transferase family with homology to prokaryotic 2-hydroxychromene-2-carboxylate isomerases. Biochem. J. 2004; 379:541-552

[104] Jakobsson P-J,Morgenstern R, Mancini J, Ford-Hutchinson A, Persson B. Common structural features of MAPEGda widespread superfamily of membrane associated proteins with highly divergent functions in eicosanoid and glutathione metabolism. Protein Sci., 1999; 8:689-692

[105] Dorion S, Lambert H, Landry J. Activation of the p38 signaling pathway by heat shock involves the dissociation of glutathione S-transferase Mu from Ask1. J. Biol. Chem., 2002; 277:30792-30797

[106] Adler V, Yin Z, Fuchs SY, Benezra M, Rosario L, et al. Regulation of JNK signaling by GSTp. EMBO J. 1999; $18: 1321-1334$

[107] Manevich Y, Feinstein SI, Fisher AB. Activation of the antioxidant enzyme 1-CYS peroxiredoxin requires glutathionylation mediated by heterodimerization with pGST. Proc. Natl. Acad. Sci. U S A. 2004; 101:3780-3785.

[108] Kinnula VL, Lehtonen S, Kaarteenaho-Wiik R, Lakari E, Pääkkö P, et al. Cell specific expression of peroxiredoxins in human lung and pulmonary sarcoidosis. Thorax. 2002; $57: 157-164$

[109] Dubuisson M, Vander Stricht D, Clippe A, Etienne F, Nauser T, et al. Human peroxiredoxin 5 is a peroxynitrite reductase. FEBS Lett. 2004; 571:161-165

[110] Holmgren A. Antioxidant functions of thioredoxin and glutaredoxin systems. Antioxid. Redox Signal. 2000; 2:811820

[111] Hensley K, Benakass EJ, Bolli R, et al. New perspectives on vitamin E: $\gamma$-tocopherol and carboxyethylhydroxychroman metabolites in biology and medicine. Free Rad. Biol. Med., 2004; 36:1-15.

[112] Pryor WA. Vitamin E and heart disease: basic science to clinical intervention trials. Free Rad. Biol. Med., 2000; 28:141-64.

[113] Kojo S. Vitamin C: basic metabolism and its function as an index of oxidative stress. Curr. Med. Chem., 2004; 11:104164.

[114] Naziroglu M, Butterworth P. Protective effects of moderate exercise with dietary vitamin $\mathrm{C}$ and $\mathrm{E}$ on blood antioxidative defense mechanism in rats with streptozotocin-induced diabetes. Can. J. Appl. Physiol., 2005; 30:172-85.

[115] Yuanyuan C., Guangyan L., Jiao Y., Yuanyuan W., Xiaoqiong Y., Xiaoyun W., Guoping L., Zhiguang L. and Nanshan Z. Vitamin C Mitigates Oxidative Stress and Tumor Necrosis Factor-Alpha in Severe Community-Acquired Pneumonia and LPS-Induced Macrophages. Mediators of Inflammation Article ID 426740, 2014; 11 pages. 
[116] Khalid R. Studies on free radicals, antioxidants, and co-factors (Review). Clinical Interventions in Aging. 2007; 2(2):219-236

[117] Stahl W, Sies H. Antioxidant activity of carotenoids. Mol. Aspect Med., 2003; 24:345-51.

[118]El-Agamey A, Lowe GM, McGarvey DJ, Mortensen A, Phillip DM, Truscott TG. Carotenoid radical chemistry and antioxidant/pro-oxidant properties. Arch. Biochem. Biophys., 2004; 430:37-48.

[119] Mortensen A, Skibsted LH, Truscott TG. 2001. The interaction of dietary carotenoids with radical species. Arch. Biochem. Biophs., 2001; 385:13-19.

[120] Niles RM. Signaling pathways in retinoid chemoprevention and treatment of cancer. Mutat. Res., 2004; 555:81-96.

[121] Donato LJ, Noy N. Suppression of mammary carcinoma growth by retinoic acid: proapoptotic genes are targets for retinoic acid receptor and cellular retinoic acid-binding protein II signaling. Cancer Res., 2000; 65:8193-8199.

[122] Niizuma H, Nakamura Y, Ozaki T, Nakanishi H, Ohira M, et al. Bcl-2 is a key regulator for the retinoic acid-induced apoptotic cell death in neuroblastoma. Oncogene. 2006; 25:5046-5055.
[123] Masella R, Di Benedetto R, Vari R, et al. Novel mechanisms of natural antioxidant compounds in biological systems: involvement of glutathione and glutathione-related enzymes. J. Nutr. Biochem., 2005; 16:577-86.

[124] Karoui H, Hogg N, Frejaville C, et al. Characterization of sulfur-centered radical intermediates formed during the oxidation of thiols and sulfite by peroxynitrite. ESR-spin trapping and oxygen uptake studies. J. Biol. Chem., 1996; 271:6000-9

[125] Dröge W. 2002. Aging-related changes in the thiol/disulfide redox state: implications for the use of thiol antioxidants. Exper. Geront., 2002 ; 37:1333-45.

[126] Smith AR, Shenvi SV, Widlansky M, et al. Lipoic acid as a potential therapy for chronic diseases associated with oxidative stress. Curr. Med. Chem., 2004; 11:1135-46.

[127] Navari-Izzo F, Quartacci MF, Sgherri C. Lipoic acid: a unique antioxidant in the detoxification of activated oxygen species. Plant Physiol. Biochem., 2002; 40:463-70.

[128] Rahimi R, Nikfar S, Larijani B, et al. A review on the role of antioxidants in the management of diabetes and its complications. Biomed. Pharmacothe., 2005; 59:365-73. 